\title{
Editorial
}

\section{Wireless Internet, Multimedia, and Artificial Intelligence: New Applications and Infrastructures}

\author{
Roberto Saia ${ }^{1, *(\mathbb{D})}$, Salvatore Carta ${ }^{1}(\mathbb{C})$ and Olaf Bergmann ${ }^{2}(\mathbb{C})$ \\ 1 Department of Mathematics and Computer Science, University of Cagliari, 09124 Cagliari, Italy; \\ salvatore@unica.it \\ 2 Department of Mathematics and Computer Science, University of Bremen, D-28359 Bremen, Germany; \\ bergmann@tzi.org \\ * Correspondence: roberto.saia@unica.it
}

check for

updates

Citation: Saia, R.; Carta, S.; Bergmann, O. Wireless Internet, Multimedia, and Artificial Intelligence: New Applications and Infrastructures. Future Internet 2021 13, 240. https://doi.org/10.3390/ fi13090240

Received: 14 September 2021 Accepted: 17 September 2021 Published: 21 September 2021

Publisher's Note: MDPI stays neutral with regard to jurisdictional claims in published maps and institutional affiliations.

Copyright: (c) 2021 by the authors. Licensee MDPI, Basel, Switzerland. This article is an open access article distributed under the terms and conditions of the Creative Commons Attribution (CC BY) license (https:// creativecommons.org/licenses/by/ $4.0 /)$.

\begin{abstract}
The potential offered by the Internet, combined with the enormous number of connectable devices, offers benefits in many areas of our modern societies, both public and private. The possibility of making heterogeneous devices communicate with each other through the Internet has given rise to a constantly growing scenario, which was unthinkable not long ago. This unstoppable growth takes place thanks to the continuous availability of increasingly sophisticated device features, an ever-increasing bandwidth and reliability of the connections, and the ever-lower consumption of the devices, which grants them long autonomy. This scenario of exponential growth also involves other sectors such as, for example, that of Artificial Intelligence (AI), which offers us increasingly sophisticated approaches that can be synergistically combined with wireless devices and the Internet in order to create powerful applications for everyday life. Precisely for the aforementioned reasons, the community of researchers, year by year, dedicates more time and resources in this direction. It should be observed that this happens in an atypical way concerning the other research fields, and this is because the achieved progress and the developed applications have practical applications in numerous and different domains.
\end{abstract}

Keywords: internet; wireless; multimedia; artificial intelligence; machine learning; ubiquitous computing; wireless sensor; networks; Internet of Things; security; deep neural networks; big data

\section{Introduction}

The increasing power of the connected devices, as well as the continuous improvements in terms of reliability and bandwidth of the Internet, have given rise to the so-called data age since an ever-increasing number of devices generate a continuous flow of information. This data flow can be exploited to our advantage, although it exposes us to risks in terms of security and privacy. For this reason, in recent years, we have witnessed an increase in investments in research, both in terms of money and human resources, in order to exploit the potential of this scenario and reduce the related risks.

Therefore, massive data generation, which is mainly related to the capability of connecting heterogeneous devices, represents a distinctive mark of our age, but these stimulating technological opportunities must be properly managed, as the ever-increasing potentialities often do not go hand in hand with efficient implementations in terms of both functionality and security.

For this reason, the idea behind our Special Issue was that of bringing together scientists from a large variety of research areas, as to face multiple aspects of the scenario taken into account, believing that the meeting between ideas from people that belong to different research areas can bring advantages to each of them. 


\section{Contributions}

This Special Issue of Future Internet received valuable contributions, both in terms of fundamental and applied research papers and high-quality surveys.

An example of this is the work in [1], where the authors present an innovative approach for damage detection of infrastructures on-edge devices by exploiting a braininspired algorithm, or in [2], where, instead, two techniques aimed at supporting the user in making privacy choices about sharing personal content online have been proposed by the authors. Another interesting work, which aimed to estimate the perceived quality of service (PQoS) of video conferencing using only 802.11-specific network performance parameters collected from Wi-Fi access points (APs) on customer premises, has been proposed in [3].

A completely different but important domain is that of the work proposed in [4], where the authors propose a method for extracting implicit answers from large tweet collections, with the aim of collecting tweets related to heart attacks, which contain useful information. The contribution in [5], which is focused on network security, first provides an extensive overview of the scenario, then proposes a novel Local Feature Engineering (LFE) approach, which is based on a data pre-processing strategy, to face some wellknown problems that affect state-of-the-art solutions. The application of a solar-powered unmanned aerial vehicle (UAV) for securing communication with a ground node in the presence of eavesdroppers in urban environments has been considered in [6], whereas a study aimed at identifying the most probable future development of social media over the next five to ten years has been provided in [7].

As for the surveys, in [8], the authors provide an extensive study of various localization techniques and classified them based on centralized, distributed, iterative, rangebased, range-free, device-based, device-free, and their sub-types, discussing the problems, challenges, various technologies, and available approaches, as well as the localization applications for a smart city such as services, infrastructure, mobility, transport, and health. Some innovative fruition modalities of cultural heritage sites have been discussed in the survey in [9], where the authors propose an approach based on User Localization, Multimodal Interaction, User Understanding, and Gamification. Lastly, the research domain related to the Free-Space Optical Communication (FSOC) has been taken into account in the survey proposed in [10].

Acknowledgments: We wish to thank all the authors involved in the submitted papers, as well as all the reviewers for their precious work, and the Future Internet journal for the valuable support at every stage of the publication process of our Special Issue.

Conflicts of Interest: The authors declare no conflict of interest.

\section{References}

1. Barchi, F.; Zanatta, L.; Parisi, E.; Burrello, A.; Brunelli, D.; Bartolini, A.; Acquaviva, A. Spiking Neural Network-Based Near-Sensor Computing for Damage Detection in Structural Health Monitoring. Future Internet 2021, 13, 219. [CrossRef]

2. Contu, F.; Demontis, A.; Dessì, S.; Muscas, M.; Riboni, D. AI-Based Analysis of Policies and Images for Privacy-Conscious Content Sharing. Future Internet 2021, 13, 139. [CrossRef]

3. Morshedi, M.; Noll, J. Estimating PQoS of Video Conferencing on Wi-Fi Networks Using Machine Learning. Future Internet 2021, 13, 63. [CrossRef]

4. Karajeh, O.; Darweesh, D.; Darwish, O.; Abu-El-Rub, N.; Alsinglawi, B.; Alsaedi, N. A Classifier to Detect Informational vs. Non-Informational Heart Attack Tweets. Future Internet 2021, 13, 19. [CrossRef]

5. Carta, S.; Podda, A.S.; Recupero, D.R.; Saia, R. A local feature engineering strategy to improve network anomaly detection. Future Internet 2020, 12, 177. [CrossRef]

6. Huang, H.; Savkin, A.V. Autonomous Navigation of a Solar-Powered UAV for Secure Communication in Urban Environments with Eavesdropping Avoidance. Future Internet 2020, 12, 170. [CrossRef]

7. Studen, L.; Tiberius, V. Social Media, Quo Vadis? Prospective Development and Implications. Future Internet 2020, $12,146$. [CrossRef]

8. Ghorpade, S.; Zennaro, M.; Chaudhari, B. Survey of Localization for Internet of Things Nodes: Approaches, Challenges and Open Issues. Future Internet 2021, 13, 210. [CrossRef] 
9. Augello, A.; Infantino, I.; Pilato, G.; Vitale, G. Site Experience Enhancement and Perspective in Cultural Heritage Fruition-A Survey on New Technologies and Methodologies Based on a "Four-Pillars" Approach. Future Internet 2021, 13, 92. [CrossRef]

10. Garlinska, M.; Pregowska, A.; Masztalerz, K.; Osial, M. From mirrors to free-space optical communication-Historical aspects in data transmission. Future Internet 2020, 12, 179. [CrossRef] 